\title{
Subjective memory complaints and concurrent memory performance in older patients of primary care providers
}

\author{
BETH E. SNITZ, ${ }^{1}$ LISA A. MORROW, ${ }^{2}$ ERIC G. RODRIGUEZ, ${ }^{3,4}$ KIMBERLY A. HUBER, ${ }^{1}$ \\ AND JUDITH A. SAXTON ${ }^{1}$ \\ ${ }^{1}$ Department of Neurology, University of Pittsburgh, Pittsburgh, Pennsylvania \\ ${ }^{2}$ Department of Psychiatry, University of Pittsburgh, Pittsburgh, Pennsylvania \\ ${ }^{3}$ Department of Medicine, University of Pittsburgh, Pittsburgh, Pennsylvania \\ ${ }^{4}$ Benedum Geriatric Center, University of Pittsburgh Medical Center, Pittsburgh, Pennsylvania
}

(Received March 14, 2008; Final Revision July 14, 2008; Accepted July 16, 2008)

\begin{abstract}
Subjective memory complaints (SMCs) are known to be inconsistently related to current memory impairment in older adults but this association has not been well investigated in primary care provider (PCP) settings. To characterize the complexity of the relationship between SMCs and objective memory in older outpatients of PCPs, we collected neuropsychological, subjective memory, depression and medical chart data from outpatients aged 65 and older, without documented dementia diagnoses, in eleven PCP offices in and around the Pittsburgh metropolitan area. Results indicated that self-estimates of current memory ability were most strongly associated with objective memory performance; in contrast, perception of worsening memory over the past year showed no association; and specific memory-related activities were only weakly associated. Women were more likely than men to show inconsistency between SMCs and objective memory performance. Only two of the 11 most significantly memory-impaired participants endorsed SMCs and only four had PCP chart documentation of memory problems. Eliciting SMCs in non-demented older adults can be of clinical value in a PCP setting, but significant limitations of patient self-report in more memory-impaired patients underscore the need to develop brief, objective indicators of memory impairment for PCP office use when there is suspicion of decline. (JINS, 2008, 14, 1004-1013.)
\end{abstract}

Keywords: Dementia, Neuropsychology, Neuropsychological tests, Mild cognitive impairment, Primary health care, Signs and symptoms

\section{INTRODUCTION}

Memory complaints are common among older adults and often considered a sign of cognitive impairment, possibly even heralding prodromal Alzheimer's disease. Indeed, the presence of subjective memory complaints (SMCs) or changes, as reported by the individual or a knowledgeable informant, was a critical component of Petersen's original conceptualization of Mild Cognitive Impairment (MCI) (Petersen et al., 1999) and is currently included in the general criteria recommended by the International Working Group on MCI (Winblad et al., 2004). However, the research

Correspondence and reprint requests to: Beth E. Snitz, Department of Neurology, University of Pittsburgh, 3471 Fifth Avenue, Pittsburgh, PA 15213. E-mail: snitzbe@upmc.edu literature is quite variable regarding the significance of SMCs, with some studies reporting an association with current memory ability (Gagnon et al., 1994; Jonker et al., 1996) or future cognitive decline (Geerlings et al., 1999; Jorm et al., 2001; Schmand et al., 1996; Wang et al., 2004), and other studies reporting a lack of association (Clement et al., 2008; Flicker et al., 1993; Jungwirth et al., 2004; Smith et al., 1996). Associations have also been reported between SMCs and biological features of Alzheimer's disease in non-demented individuals, such as Alzheimer neuropathology (Barnes et al., 2006), hippocampal volume (van der Flier et al., 2004) and apolipoprotein E4 allele (Small et al., 1999; Stewart et al., 2001), whereas other studies report lack of association (Harwood et al., 2004). Even further complicating the relationship between SMCs and prodromal Alzheimer's disease is the well documented phe- 
nomenon of "metamemory" deficits, or impaired awareness of memory deficits in some patients within the early course of the disease (Feher et al., 1994; Souchay, 2007).

A recent narrative review of cognition-related, population studies of older adults (Reid \& Maclullich, 2006) concluded that SMCs are inconsistently related to current cognitive impairment, whereas the evidence seems stronger for an association with future cognitive decline. Depression and some personality traits (e.g., neuroticism) are consistent correlates of SMCs when measured in any given study, but often there is no consideration of the role of moodrelated variables in the association between SMCs and cognitive impairment. Thus, as an indicator of objectively measured impairment, the concurrent validity of SMCs in older adults is not well established, nor are the factors which constrain validity well understood.

As the population ages, primary care providers (PCPs) are increasingly becoming a critical "frontline" of dementia detection and treatment (Ganguli et al., 2004b). Because there is no universal, routine dementia screening standard recommended by the US Preventive Services Task Force (Boustani et al., 2003), PCPs often rely heavily on subjective memory complaints, from patient or family, when deciding whether or not to take action (e.g., prescribing cholinesterase inhibitors, making referrals, ordering laboratory tests or neuropsychological testing, etc.) (Franz et al., 2007). Yet very few studies have examined the validity of SMCs within a PCP setting (Derouesne et al., 1993; Lavery et al., 2007). In addition, there is a need for research comparing the usefulness of different kinds of questions a PCP might ask to elicit information about everyday memory problems, given limited time in an office visit. For instance, is it best to ask specific questions, such as whether an older patient misplaces items or forgets appointments? If so, which specific memory problems are clinically meaningful? Should one ask about subjective change over time, or about current memory functioning? The possible approaches to eliciting and assessing SMCs are highly variable in the literature (Reid \& Maclullich, 2006) and there is no consensus regarding which aspects of patientreported subjective memory complaints are most predictive of cognitive impairment.

Another set of research questions potentially useful for clinicians involved in primary care relates to who is likely to under-report or over-report SMCs. PCPs who see older patients are likely to encounter both kinds of inaccurate reporting: patients who complain of everyday memory problems but show no objective evidence of cognitive impairment on follow-up, and those who do not complain but are, in fact, clinically impaired-eventually identified through the family expressing concerns, the physician's clinical impression, and so forth (Franz et al., 2007).

The present study examined the association between subjective memory complaints and concurrent cognitive performance among older patients in PCP offices. Strengths of the study include use of a multi-domain neuropsychological test battery designed to detect pre-dementia states (e.g.,
MCI), an in-depth assessment of subjective memory complaints, including general self-ratings and a range of specific memory-related symptoms, and consideration of the role of depressive symptoms. We hypothesized that SMCs would be significantly related to cognitive test performance independent of depressive symptoms. Secondary questions included: (a) Which type of questions soliciting SMCs (e.g., general vs. specific complaints; current selfratings vs. change over time) are most valid indicators of objective memory functioning? (b) Which specific everyday memory symptoms best discriminate between patients with good and poor memory functioning? (c) Which patients are likely to show inconsistency between subjective complaints and objective performance? (d) What proportion of patients with identified memory impairment endorse subjective complaints?

\section{METHODS}

\section{Participants}

Data for this study were collected as part of a larger study examining the utility of providing cognitive testing of older adults in the PCP office. Participants included the first 276 consecutive primary care patients consented into the parent study from eleven PCP practices in the greater Pittsburgh and surrounding areas. Two of the practices were located in urban settings, two in rural settings, and seven in suburban settings. Patients in these practices were initially recruited if they: (1) were aged 65 and over, and (2) did not have medical chart diagnosis of dementia (i.e., no record of "dementia" or "Alzheimer disease" or similar terms, or other specific dementia diagnoses). Observations or reports of memory problems were not exclusion criteria. The goal of the inclusion/exclusion criteria was to be inclusive regarding actual level of cognitive function (e.g., we expected some participants to score within the range of dementia on neuropsychological testing, given the low rates of dementia detection in PCP settings [e.g., (Ganguli et al., 2004b)]. Prospective participants over 65 were approached initially by their own PCPs, regardless of the reason for their visit to the doctor (e.g., well-visit, present illness, etc.) although all participants who eventually consented were only tested when not acutely ill. Following a telephone screening and initial consent and interview, potential participants were excluded if they had significant sensory deficits, which would preclude cognitive testing, or a Mini Mental State Exam (MMSE) (Folstein et al., 1975) score of 18 or less. This cutoff was chosen to identify individuals who may be significantly cognitively impaired and possibly at risk to themselves or others (e.g., continuing to drive, etc.) but who had not been previously identified by their PCP as having dementia. In these cases the study blind (randomized to neuropsychological feedback group or treatment-as usual, TAU) was broken and the PCP was notified of the individual's cognitive status. 
Ninety-one individuals were referred by their PCPs but did not consent to the study. There were no significant differences between the proportions of these patients and those who did consent regarding originating study doctor, $\mathrm{PCP}$ office, geographical classification of PCP offices, or assignment of PCP office to intervention or TAU group.

This study was approved by the University of Pittsburgh Institutional Review Board and was conducted in accordance with the Helsinki Declaration with all participants providing written informed consent.

\section{Neuropsychological Assessment}

All participants completed a neuropsychological battery tapping multiple domains and designed to detect mild cognitive deficits and pre-dementia cognitive changes. Memory tests included the Consortium to Establish a Registry for Alzheimer's Disease (CERAD) Word List Learning Test (WLL) (Morris et al., 1989) with delayed recall, Wechsler Memory Scale-Revised (WMS-R) Logical Memory (LM) I and II (Wechsler, 1987), and the modified Rey-Osterrieth (mR-O) figure immediate and delayed recall (Becker et al., 1987). Tests of attention/psychomotor speed included WMS-R Digit Span forward, Trail Making Test part A (Reitan, 1958), and Wechsler Adult Intelligence ScaleRevised (WAIS-R) Digit Symbol (Wechsler, 1981). Visuospatial tests included a modified WAIS-R Block Design and copy of the modified Rey-Osterrieth figure. Tests of language abilities included the Boston Naming Test (Kaplan et al., 2001), letter fluency (number of letters starting with "F," "A," and "S" in 60 seconds each; FAS) and semantic fluency (animals) (Spreen \& Strauss, 1998). Executive functions tests included Trail Making Test part B, WMS-R Digit Span backward and clock drawing.

\section{Subjective Memory Assessment}

Standardized questions were developed to assess various aspects of subjective memory performance (Ganguli et al., 2004a). These questions were administered prior to the neuropsychological evaluation as an interview to participants and included general/global questions related to current functioning (i.e., "In general, how good do you feel your memory is for a person your age"?) and change over the past year (i.e., "In general, do you feel you remember things less well than you did a year ago"'?) Response options were a forced-choice anchored rating for the former question ("poor," "fair," "good," "excellent") and "yes/no" for the latter. Also included were 14 specific items assessing perception of change in the past year on specific memoryrelated problems or activities in daily life, such as "remembering appointments, messages, etc," "remembering names of people you've known for a long time," "remembering where you've put things that you use often"? etc. (See Appendix 1 for complete list of items). Response choices were "worse," "same," or "better" than one year ago. Finally, participants who endorsed "worse" on any of the specific items were asked if they were "worried about these problems with remembering"? ("yes/no") and if they had "talked to (their) doctor/nurse about these problems"? ("yes/no").

\section{Other Assessments and Medical Record Review}

Participants also completed a modified version of the Center for Epidemiological Studies-Depression (mCES-D) scale (Ganguli et al., 1995). They completed questionnaires on demographic information, activities of daily living (ADLs; modified Older Americans Resources and Services scale) (McDowell \& Newell, 1987), and instrumental ADLs (modified Alzheimer's Disease Functional Assessment and Change scale) (Galasko et al., 1997). In addition, participant medical records over two years preceding study entry were reviewed. Abstracted medical chart information included medical problem list, medications, ER visits, hospitalizations, surgeries, evidence of work-up for dementia, and any documented note of memory loss/confusion/ disorientation/getting lost/or short-term memory problems, whether reported by or elicited from the patient, a family member, observed by the PCP or communicated by another provider. With regard to medications, generic or trade name, dose, and dosing schedule were documented. Medications classified as "psychoactive" included the following: all anxiolytic agents including benzodiazepines, narcotic analgesics, opiate agonists, antipsychotics, sedatives, hypnotics, and tricyclic antidepressants.

\section{Statistical Analyses}

Associations between objective cognitive performance and global subjective memory questions were tested via one-way Analysis of Variance (ANOVA), with subjective memory responses as fixed independent variables and neuropsychological measures as dependent variables. Responses for the 14 specific memory-related items were dichotomized as 1 ("worse") versus 0 ("same" or "better than last year"), the sum of which resulted in a scale ranging from $0-14$ with increasing values reflecting greater number of declined activities. Associations between this specific memory-related activities scale and cognitive test performance were examined using bivariate Pearson correlations. All analyses examining the relationship between subjective and objective memory performance were performed with and without inclusion of mCES-D depression score and years of education as covariates or in partial correlations.

To evaluate which specific everyday memory symptoms best discriminate between participants with good and poor memory functioning, we used a modified item Discrimination Index (D) adapted from classical test theory. Specifically, we defined a high memory performance group (HM) and a low memory performance group (LM) based on an overall average $\mathrm{Z}$ score ( $\mathrm{Z} \_$memory) of the following 
Z-transformed memory measures: CERAD WLL total learning (trials 1-3), CERAD WLL delayed recall, mR-O Figure delayed recall, and WMS-R LM immediate and delayed recall. Following Kelley (1939, cited in Ebel, 1954), the upper and lower $27 \%$ of the distribution of Z_memory comprised the LM and HM groups, and $D$ was calculated for each specific subjective memory-related item as $D=$ $p(\mathrm{HM})-p(\mathrm{LM})$, where $p(\mathrm{HM})$ and $p(\mathrm{LM})$ are the proportions of those "passing" an item (i.e., activity reported "same" or "better) by high and low objective memory performance groups, respectively.

To explore who is likely to show inconsistency between subjective complaints and objective performance, we defined four sub-groups based on crossing a median split of $Z$ _memory with a median split of the specific memory-related activity scale described above (0-14 range). Using first omnibus ANOVA followed by Scheffé post-hoc tests, we compared sub-groups on the following participant characteristics: demographic variables, depression score, number of prescription medications, and non-memory neuropsychological variables.

Finally, participants with impaired objective memory performance were identified as having $Z$ _memory equal to or below $\mathrm{Z}=-1.50$. In this subset of participants, the proportion with medical chart-documented memory problems was determined, as well the proportion of those reporting concern about their memory, and of those having spoken to their doctor about memory concerns.

\section{RESULTS}

Table 1 presents demographic and clinical characteristics of the total participant sample. Of note, the mean MMSE score was high (28.2), as expected due to exclusion of potential participants with chart diagnoses of dementia, although there was a clinically significant range of scores (21-30). As well, the number of participants reporting any difficulty with basic or instrumental activities of daily living (19.6\%) and those with documented memory problems in their PCP chart (15.2\%) suggests the presence of significant cognitivelyrelated difficulties in about $15 \%$ to $20 \%$ of the sample. The mean depression score was very low, but with a clinically significant range present.

\section{Association Between a Global Self-Rating of Memory and Objective Test Performance.}

Table 2 presents mean memory and non-memory test scores grouped according to global memory self-ratings ("In general, how good do you feel your memory is for a person your age"?). As only one participant responded "poor" to this item, responses "fair" and "poor" were combined. All six mean memory measures (from 3 tests) were significantly different among self-rating groups, with means ordered in the expected direction (i.e., highest means for the "excellent" self-rating group, lowest for the "fair/poor"
Table 1. Demographic and clinical characteristics of participants (total $n=276$ )

\begin{tabular}{lccc}
\hline \hline & $\begin{array}{c}\text { Mean } \\
\text { or } n\end{array}$ & $\begin{array}{c}\text { (SD) } \\
\text { or } \%\end{array}$ & Range \\
\hline Age, mean (SD) & 73.2 & $(5.6)$ & $65-93$ \\
Education (years), mean (SD) & 14.0 & $\begin{array}{l}(3.0) \\
\text { Females, } n \text {, } \%\end{array}$ & $6-25$ \\
MMSE score, mean (SD) & 280 & $58.0 \%$ & - \\
mCES-D score (0-20 points), & 1.9 & $(1.7)$ & $21-30$ \\
$\quad$ mean (SD)* & & & $0-15$ \\
Any ADL/IADL difficulties, $n, \% \dagger$ & 54 & $19.6 \%$ & - \\
Number of prescription medications, & 5.4 & $(3.0)$ & $0-17$ \\
$\quad$ mean (SD) & & & \\
Taking any psychoactive medication, $n \%$ & 43 & $15.6 \%$ & - \\
Medical chart note (active or past) of: & & & \\
$\quad$ Hypertension, $n, \%$ & 198 & $71.7 \%$ & - \\
Hypercholesterolemia, $n, \%$ & 203 & $73.6 \%$ & - \\
Coronary artery disease, $n, \%$ & 72 & $26.1 \%$ & - \\
Stroke, $n, \%$ & 15 & $5.4 \%$ & - \\
$\quad$ Diabetes mellitus II, $n, \%$ & 77 & $27.9 \%$ & - \\
$\quad$ Memory loss, $n, \%$ & 42 & $15.2 \%$ & - \\
\hline \hline
\end{tabular}

MMSE $=$ Mini Mental State Exam; ADL = activities of daily living; mCES-D = modified Center for Epidemiologic Studies Depression Scale; $\mathrm{ADL}=$ activities of daily living; $\mathrm{IADL}=$ instrumental activities of daily living.

*Higher scores indicate a greater number of depression symptoms. $\dagger$ Self-reported.

group). One non-memory measure, Digit Symbol, was also significantly different in means among the self-rating groups. Among the non-cognitive measures, the groups significantly differed on mCES-D score, with the highest mean depression score in the "fair/poor" self-rating group. Of note, although self-rating groups differed across all memory measures, the degree of variability in memory test scores that can be attributed to memory rating was low; that is, $\eta^{2}$, equivalent to an $\mathrm{R}^{2}$ obtained in regression models, ranged from $3.2 \%$ to $6.9 \%$, representing small effect sizes of association (Cohen, 1988).

After including mCES-D score and years of education as covariates in the univariate ANOVA models, the pattern of results was unchanged except for Digit Symbol, which no longer significantly differed among memory self-rating groups $(P=.181)$.

\section{Association Between Perceived One-Year Change in Memory and Objective Test Performance}

When asked "In general, do you feel you remember things less well than you did a year ago"? 99 (35.9\%) of participants responded "yes," whereas 177 (64\%) responded "no." These two groups were not significantly different on any of the six memory measures or demographic variables (all $P$ 's $>$ .30 ), although the former group had a significantly higher mean mCES-D score than the latter group (2.6 vs. 1.5, respectively). 
Table 2. Mean ( \pm SD) memory, non-memory, and non-cognitive measures by level of global memory self-rating

\begin{tabular}{|c|c|c|c|c|c|}
\hline & \multicolumn{3}{|c|}{ Global self-rating of memory "for age" } & \multirow[t]{2}{*}{$P$-value } & \multirow[t]{2}{*}{$\begin{array}{l}\text { Eta-squared } \\
\qquad\left(\eta^{2}\right)\end{array}$} \\
\hline & $\begin{array}{c}\text { "Excellent" } \\
(n=46)\end{array}$ & $\begin{array}{c}\text { "Good" } \\
(n=167)\end{array}$ & $\begin{array}{l}\text { "Fair" or "Poor" } \\
\quad(n=63)\end{array}$ & & \\
\hline \multicolumn{6}{|l|}{ Memory measures } \\
\hline CERAD WLL total learning & $20.5(4.9)$ & $19.8(4.2)$ & $18.3(4.1)$ & .021 & $2.8 \%$ \\
\hline CERAD WLL delayed recall & $5.9(2.9)$ & $5.6(2.4)$ & $4.5(2.7)$ & .004 & $3.9 \%$ \\
\hline WMS-R Logical Memory I & $24.4(7.9)$ & $22.4(6.8)$ & $19.5(7.4)$ & .001 & $4.7 \%$ \\
\hline WMS-R Logical Memory II & $20.4(8.7)$ & $18.2(7.1)$ & $14.2(8.2)$ & $<.001$ & $6.9 \%$ \\
\hline Modified R-O figure immediate recall (24 points) & $16.3(4.5)$ & $15.9(4.1)$ & $14.1(4.7)$ & .009 & $3.4 \%$ \\
\hline Modified R-O figure delayed recall (24 points) & $14.6(5.2)$ & $15.3(4.2)$ & $13.2(5.4)$ & .011 & $3.2 \%$ \\
\hline \multicolumn{6}{|l|}{ Non-memory measures } \\
\hline Trail Making A (seconds) & $40.5(17.7)$ & $41.3(20.0)$ & $43.8(19.5)$ & $>.5$ & $0.4 \%$ \\
\hline Trail Making B (seconds) & $112.9(66.3)$ & $107.7(61.2)$ & $120.0(61.4)$ & $>.4$ & $0.6 \%$ \\
\hline WAIS-R Digit Symbol & $46.2(12.2)$ & $45.1(10.9)$ & $41.2(11.6)$ & .033 & $2.5 \%$ \\
\hline Boston Naming Test & $54.9(4.2)$ & $53.3(5.1)$ & $52.5(6.6)$ & .062 & $2.0 \%$ \\
\hline Letter fluency (FAS) & $38.7(12.1)$ & $36.7(13.3)$ & $34.1(10.9)$ & $>.1$ & $1.3 \%$ \\
\hline Modified R-O figure copy (24 points) & $20.9(2.2)$ & $20.6(2.5)$ & $19.9(2.7)$ & .088 & $1.8 \%$ \\
\hline \multicolumn{6}{|l|}{ Non-cognitive measures } \\
\hline Age, years & $73.9(6.4)$ & $72.7(5.7)$ & $74.2(5.7)$ & $>.1$ & $1.4 \%$ \\
\hline Education, years & $14.6(2.8)$ & $14.0(3.0)$ & $13.6(2.9)$ & $>.2$ & $1.0 \%$ \\
\hline mCES-D score $\dagger(0-20$ points $)$ & $1.8(2.6)$ & $1.5(2.2)$ & $2.9(3.0)$ & .001 & $5.1 \%$ \\
\hline Number prescription medications & $4.8(3.0)$ & $5.4(2.9)$ & $5.6(3.1)$ & $>.3$ & $0.8 \%$ \\
\hline
\end{tabular}

Note. After including mCES-D (depression) score and education as covariates in the univariate Analysis of Variance models, the pattern of significant memory self-rating effects on cognitive variables was unchanged except for Digit Symbol, which no longer significantly differed among memory self-rating groups $(P=.181)$.

CERAD WLL $=$ Consortium to Establish a Registry for Alzheimer's Disease Word List Learning Test; WMS-R Wechsler Memory Scale, Revised; R-O = Rey Osterrieth Figure; WAIS-R = Wechsler Adult Intelligence Scale, Revised; mCES-D = modified Center for Epidemiologic Studies Depression Scale. $\dagger$ Higher scores indicate a greater number of depression symptoms.

\section{Associations Between Specific Memory-Related Activities and Objective Test Performance}

Of the six memory measures examined, only WLL learning and WLL delayed recall were significantly correlated $(P<$ .05 , one-tailed) with the specific memory-related activities scale ( $r=-0.14$ and $r=-0.19$, respectively), indicating test performance was inversely and weakly associated with endorsed 'worsening' of specific activities. The mCES-D score was also significantly correlated with specific memoryrelated problems $(r=0.26)$, while age and education were not. Partial correlations between the specific activities scale and the six memory test measures, controlling for mCES-D score, were unchanged in significance and size of effects.

\section{Item Discrimination of Individual, Specific Memory-Related Activities}

Discrimination Index $(D)$ values for the 14 specific memoryrelated activities ranged from -0.013 to 0.170 . The maximum possible value of $D$ is 1.0 , when all persons in the upper ability group pass an item and all in the lower ability group fail that item. Test items with $D$ in the range of 0.20 are considered to have low but minimally acceptable dis- crimination (Ebel, 1954). The highest value observed ( $D=$ 0.170 ), just barely approaching this minimally acceptable range, was for the item "Remembering things that happened or were said a few days ago," representing the difference between the proportions of participants "passing" that item (endorsing "no change" or "better") in the High Memory group (87.8\% passed) and the Low Memory group (70.3\% passed). Of note, all the remaining specific memoryrelated activity items had $D$ 's less than 0.08 , indicating very low or essentially zero item discrimination. For instance, the item with the overall highest rate of complaint, "Finding the right word to use to describe something you know well" (36.6\% overall reported they were "worse" compared to last year), had one of the lowest $D$ values at -0.013 , indicating this item does not reliably discriminate between upper and lower memory ability groups.

\section{Inconsistency between Subjective Memory Complaints and Objective Memory Performance}

Table 3 presents four sub-groups of participants based on their standing in median splits of $Z \_$memory and the 14-item specific memory-related activities scale. Post-hoc analyses revealed an overall pattern of mean cognitive scores (non- 
Table 3. Characteristics of sub-groups based on crossed median splits of subjective and objective memory functioning

\begin{tabular}{|c|c|c|c|c|c|}
\hline & \multicolumn{4}{|c|}{ Subjective memory functioning } & \multirow[b]{3}{*}{$\begin{array}{l}P \text {-value } \\
\left(\mathrm{F} \text { or } \chi^{2}\right)\end{array}$} \\
\hline & \multicolumn{2}{|c|}{ High } & \multicolumn{2}{|c|}{ Low } & \\
\hline & $\begin{array}{l}\text { Objective } \\
\text { Memory } \\
\text { High } \\
(n=56)\end{array}$ & $\begin{array}{l}\text { Objective } \\
\text { Memory } \\
\text { Low } \\
(n=53)\end{array}$ & $\begin{array}{l}\text { Objective } \\
\text { Memory } \\
\text { High } \\
(n=82)\end{array}$ & $\begin{array}{l}\text { Objective } \\
\text { Memory } \\
\text { Low } \\
(n=85)\end{array}$ & \\
\hline Age, years, mean (SD) & $72.1^{\mathrm{a}}(5.6)$ & $74.1^{\mathrm{a}}(5.7)$ & $72.3^{\mathrm{a}}(5.1)$ & $74.4^{\mathrm{a}}(6.7)$ & .03 \\
\hline Education, years, mean (SD) & $14.4(2.9)$ & $13.4(2.8)$ & $14.4(2.8)$ & $13.4(3.3)$ & .127 \\
\hline Gender, $n(\%)$ female & $31(54.4 \%)$ & $33(62.3 \%)$ & $58(71.6 \%)$ & $37(43.5 \%)$ & .003 \\
\hline mCES-D, mean (SD) (0-20 points)* & $0.80^{\mathrm{a}}(1.2)$ & $1.2^{\mathrm{a}}(1.7)$ & $2.3^{\mathrm{b}}(2.9)$ & $2.5^{\mathrm{b}}(2.8)$ & $<.001$ \\
\hline$N$ prescription medications, mean (SD) & $5.2(2.8)$ & $4.8(2.9)$ & $5.4(3.3)$ & $5.8(2.9)$ & .372 \\
\hline Taking any psychoactive medication, $n(\%)$ & $3(5.4 \%)$ & $7(13.2 \%)$ & $16(19.5 \%)$ & $17(20.05)$ & .075 \\
\hline \multicolumn{6}{|l|}{ Non-memory measures, mean (SD) } \\
\hline Trail making A (seconds) & $35.3^{\mathrm{a}}(13.4)$ & $45.3^{\mathrm{b}, \mathrm{c}}(22.2)$ & $37.1^{\mathrm{a}, \mathrm{b}}(15.3)$ & $48.2^{\mathrm{c}}(22.2)$ & $<.001$ \\
\hline Trail making B (seconds) & $83.7^{\mathrm{a}}(35.2)$ & $124.9^{\mathrm{b}}(57.2)$ & $87.4^{\mathrm{a}}(40.8)$ & $144.7^{b}(78.5)$ & $<.001$ \\
\hline WAIS-R digit symbol & $49.4^{\mathrm{a}}(8.4)$ & $41.8^{\mathrm{b}}(9.4)$ & $48.7^{\mathrm{a}}(10.7)$ & $38.6^{\mathrm{b}}(11.8)$ & $<.001$ \\
\hline Boston Naming Test & $54.9^{\mathrm{a}}(4.2)$ & $51.0^{\mathrm{b}}(6.6)$ & $55.5^{\mathrm{a}}(3.3)^{\mathrm{a}}$ & $51.8^{\mathrm{b}}(5.9)$ & $<.001$ \\
\hline Letter fluency (FAS) & $40.2^{\mathrm{a}}(12.1)$ & $33.8^{\mathrm{b}}(13.3)$ & $40.8^{\mathrm{a}}(11.1)$ & $31.5^{\mathrm{b}}(11.8)$ & $<.001$ \\
\hline Modified R-O figure copy ( 24 points) & $21.3^{\mathrm{a}}(2.2)$ & $20.2^{\mathrm{a}, \mathrm{b}}(2.7)$ & $21.2^{\mathrm{a}}(2.0)$ & $19.5^{\mathrm{b}}(2.6)$ & $<.001$ \\
\hline
\end{tabular}

Note. Means within a given row with different superscripts are statistically different at $\mathrm{p}<.05$ by Scheffé post-hoc procedure.

$\mathrm{R}-\mathrm{O}=$ Rey Osterrieth Figure; WAIS-R = Wechsler Adult Intelligence Scale, Revised; mCES-D = modified Center for Epidemiologic Studies Depression Scale.

*Higher scores indicate a greater number of depression symptoms.

memory measures) varying according to objective memory performance (high $v s$. low), while mean level of depression and psychoactive medication status varied according to subjective memory ranking (high vs. low). The only variable, which varied with "consistency" between subjective and objective memory performance was gender: among the high objective memory participants, there were proportionately more women $(72 \%)$ in low subjective memory group vs. those reporting high subjective functioning $\left(54 \% ; \chi^{2}=\right.$ 4.04, $P<.05)$. Further, within the low objective memory group, there were proportionately more women reporting higher subjective functioning (62\%) compared to those with more memory complaints $\left(44 \% ; \chi^{2}=4.58, P<.05\right)$.

\section{Participants with Identified Objective Memory Impairment}

Of the total 276 participants, $11(4 \%)$ were identified with a Z_memory score of -1.50 or less (range of $Z \_$memory $=$ -1.50 to -2.17$)$, representing a cutoff for memory impairment at least at the level of amnestic MCI (Petersen et al., 1999) if not clinical dementia (Lopez et al., 2003). Of these 11 participants, two rated their current overall memory as "excellent," five responded "good," four responded "fair" and none responded "poor." Only two of the 11 answered "yes" to "Do you feel you remember things less well than you did one year ago"? Three reported being worried about their memory and two reported having talked to their doctor about their memory. In review of their PCP medical records two years prior to the study, four of the 11 had some kind of documentation of memory loss, none had record of prescriptions for dementia-related medication, none were taking any psychoactive medications, and none had note of specialist referrals relating to memory problems or dementia evaluation.

\section{SUMMARY AND DISCUSSION}

The goal of the present study was to investigate the complexity of the relationship between SMCs and objective memory performance in older PCP outpatients in a variety of ways, given a well-established literature of weak and inconsistent relationships. We found current memory selfratings to be significantly associated with memory test performance, even after controlling for number of depressive symptoms and education. We found weaker associations with decline on specific memory-related daily activities, and we found no association with endorsement of general memory worsening in the past year.

The above results suggest that simply asking older patients in a primary care setting to self-rate their memory today (e.g., from poor to excellent) may be most effective in gauging current memory ability as measured by cognitive tests. At the group level, participants in this study were surprisingly accurate in sorting themselves by broad memory self-ratings. Considering the temporal nature of the various SMC questions, the findings are sensible: one measure of current functioning (e.g., cross-sectional test performance) should be more strongly associated with another "snap-shot" measure of current functioning (e.g., 
current self-rating of memory) than with a report of change over time. A high functioning individual may have subjectively experienced cognitive decline yet still measure aboveaverage when tested. Conversely, an individual with lifelong below-average cognitive abilities may report no memory changes, but, as expected, have low memory test scores. One would then predict change scores from repeated memory assessments in a longitudinal design would be more strongly associated with subjective reports of change, and there is some support for this in the literature (Jorm et al., 2001; Wang et al., 2004). We are currently following these participants longitudinally and will examine this hypothesis in future analyses. An important limitation to the present results, as well, is that our question about change was in reference to the past year only, and this may have been too brief a time-frame to capture clinically meaningful change. Examining subjective decline over decades or since young adulthood may yield different results and should be explored in future studies.

Individual specific memory-related activities (e.g., wordfinding, misplacing items, remembering appointments, etc.) discriminated very poorly between high and low memory ability groups. One reason is that day-to-day problems most commonly endorsed by the low memory group (e.g., remembering names of people known for a long time and those recently met) were also commonly endorsed by the high memory group. The most discriminating item was related to forgetting events and conversations from a few days ago and is consistent with the finding that anterograde memory deficits are the hallmark of early Alzheimer's disease (Backman et al., 2005; Saxton et al., 2004). However, even this item had relatively low discriminative power, suggesting, again, that inquiries about general subjective memory may be the most effective approach to eliciting meaningful clinical information in this primary care patient population.

Depressive symptoms were consistently related to all aspects of subjective memory reporting, consistent with other studies (Reid \& Maclullich, 2006). However, level of depression did not account for the relationship between objective and subjective memory, suggesting it is an independent predictor of memory complaints in this study population. In contrast, depression did account for the relationship between complex processing speed (Digit Symbol) and subjective memory rating. Overall, these results suggest that older adults who complain of memory problems are likely to have depressive symptoms, but that SMCs in the presence of mood symptoms should not be regarded by clinicians simply as signs of depression nor should they be expected to fully remit with antidepressant treatment (Bhalla et al., 2006).

Another major finding of the present study, consistent with the literature, is that the effect sizes of associations between objective and subjective memory are small even when significant (Derouesne et al., 1993; Jonker et al., 1996; Lam et al., 2005; Mol et al., 2006). For instance, variability in list learning and recall accounts for less than $3 \%$ of the variability in reported change in memory-related activities. Even depressive symptoms account for only about $5 \%$ of this variability. Clearly other factors drive the degree to which SMCs are endorsed, including personality variables (e.g., neuroticism, negative affectivity) (Dux et al., 2008; Reid \& Maclullich, 2006) and likely measurement-related variables such as social desirability bias and other response biases (e.g., "cry-for-help") (Franklin et al., 2002). Whereas these variables were not measured in the present study, we attempted to identify other features associated with "misfit" between subjective memory reporting and objective memory performance. Our data suggest that gender may be important in interpreting who reports memory problems but has good memory scores ("complainers"), and who subjectively reports good memory but has poor memory scores ("deniers"), as women were more likely than men to fall into both groups. Results also indicate that presence of depression will not be helpful for clinicians in identifying the "complainers," since, similar to Zandi (2004), depressive symptoms are elevated in individuals with SMCs regardless of whether objective memory impairment is present or not.

Finally, of 11 research participants identified conservatively as showing strong evidence of objective memory impairment, few of them endorsed SMCs. These were the most significantly memory-impaired participants in the study, the most likely to be characterized as amnestic MCI, and the most likely to represent a dementia prodrome. Their lack of reported awareness may reflect metamemory deficits (i.e., agnosognosia) well characterized in Alzheimer patients (Feher et al., 1994; Souchay, 2007). One can conclude from this that in a PCP setting, whether or not a patient endorses memory problems is an insensitive measure in identifying significant memory impairment. This underscores the need for several additional approaches clinicians may take to identify cognitive impairment, including (1) utilizing early dementia screening tools developed for PCP offices settings as objective indicators of memory function (Grober et al., 2008; Morrow et al., 2007); (2) actively seeking out information from a family member, care-giver or other informant when clinical suspicion is aroused (Carr et al., 2000); and (3) referring for neuropsychological evaluation if either of these two initial approaches suggests cognitive impairment. The fact that less than half of these memory-impaired participants had documentation of memory loss in their medical chart is consistent with reports of under-recognition of memory impairment and dementia in PCP settings (Ganguli et al., 2004b; Lavery et al., 2007; Valcour et al., 2000).

An important caveat for the present results as a whole is that eliciting SMCs using standardized questions may generate different information than might be spontaneously volunteered in a clinical encounter. Whereas the latter are not easily studied using standardized methods, they may be more valid indicators of impairment than SMCs elicited by questioning, as may be elicited responses to questions other than those asked in the present study. Another limitation of the present results includes possible constraints on their generalizability, as participant self-selection biases may have 
been present. For instance, consenters may have been more concerned about their cognitive functioning, and therefore more likely to participate; conversely, non-consenters may have had more concerns about their memory and were less likely to participate for fear of diagnostic confirmation of their worries. For these reasons, the present sample may not be representative of the population of older adult PCP patients.

The development of effective treatment and prevention interventions for Alzheimer's disease will require increasingly earlier identification of at-risk individuals (Dubois et al., 2007). In a PCP setting, subjective memory complaints typically represent a clinician's first clue that there may be a problem. However, the validity of SMCs as indicators of a developing neurodegenerative process is weak. The relationship between subjective memory complaints and objective memory impairment in older adults is complex; the major determinants of SMCs are unmeasured in most studies; finally, we do not yet understand who is likely to under-report or over-report SMCs and why. The present study was an attempt to address some of these questions, but clearly there is a great need for further research in this area to better inform and assist those on the "frontline" in the critical task of identifying at-risk and memory-impaired older adults.

\section{ACKNOWLEDGMENTS}

This study was supported by National Institute on Aging Grant R01 AG023129. The authors thank Kim Metheny, Cathy Sterling, Lori Cimino, and Sandy Giconi for invaluable assistance with data collection and management, and Graham Ratcliff for his helpful review of the manuscript. Conflict of Interest: Drs. Saxton and Morrow have worked with Psychology Software Tools (PST) as co-inventors of the CAMCI (in reference list) and, as such, have a potential financial interest in future development of the test. PST has provided no funding for the current study and had no role in the design, interpretation of results or preparation of this manuscript. All other authors report that they have no financial disclosures nor conflicts of interest related to this paper. Author Contributions: Beth Snitz: study concept and design, analysis and interpretation of data, and preparation of manuscript. Lisa Morrow: study concept and design, and preparation of manuscript. Kimberly Huber: study concept and design, acquisition of data and preparation of manuscript. Eric Rodriguez: analysis and interpretation of data, and preparation of manuscript. Judith Saxton: study concept and design, analysis and interpretation of data, and preparation of manuscript. Sponsors Role: None

\section{REFERENCES}

Backman, L., Jones, S., Berger, A.-K., Laukka, E.J., \& Small, B.J. (2005). Cognitive impairment in preclinical Alzheimer's disease: A meta-analysis. Neuropsychology, 19, 520-531.

Barnes, L.L., Schneider, J.A., Boyle, P.A., Bienias, J.L., \& Bennett, D.A. (2006). Memory complaints are related to Alzheimer disease pathology in older persons. Neurology, 67, 1581-1585.

Becker, J.T., Boller, F., Saxton, J., \& McGonigle-Gibson, K.L. (1987). Normal rates of forgetting of verbal and non-verbal material in Alzheimer's disease. Cortex, 23, 59-72.
Bhalla, R.K., Butters, M.A., Mulsant, B.H., Begley, A.E., Zmuda, M.D., Schoderbek, B., Pollock, B.G., Reynolds, C.F., 3rd, \& Becker, J.T. (2006). Persistence of neuropsychologic deficits in the remitted state of late-life depression. American Journal of Geriatric Psychiatry, 14, 419-427.

Boustani, M., Peterson, B., Hanson, L., Harris, R., Lohr, K.N., \& Force, U.S.P.S.T. (2003). Screening for dementia in primary care: A summary of the evidence for the U.S. Preventive Services Task Force. [summary for patients in Ann Intern Med. 2003 Jun 3;138(11):I60; PMID: 12779314]. Annals of Internal Medicine, 138, 927-937.

Carr, D.B., Gray, S., Baty, J., \& Morris, J.C. (2000). The value of informant versus individual's complaints of memory impairment in early dementia. Neurology, 55, 1724-1726.

Clement, F., Belleville, S., \& Gauthier, S. (2008). Cognitive complaint in mild cognitive impairment and Alzheimer's disease. Journal of the International Neuropsychological Society, 14, 222-232.

Cohen, J. (1988). Statistical power analysis for the behavioral sciences (2nd ed.). Hillsdale, NJ: Erlbaum.

Derouesne, C., Dealberto, M.J., Boyer, P., Lubin, S., Sauron, B., Piette, F., Kohler, F., \& Alperovitch, A. (1993). Empirical evaluation of the 'Cognitive Difficulties Scale' for assessment of memory complaints in general practice: A study of $1628 \mathrm{cog}$ nitively normal subjects aged $45-75$ years. International Journal of Geriatric Psychiatry, 8, 599-607.

Dubois, B., Feldman, H.H., Jacova, C., Dekosky, S.T., BarbergerGateau, P., Cummings, J., Delacourte, A., Galasko, D., Gauthier, S., Jicha, G., Meguro, K., O’Brien, J., Pasquier, F., Robert, P., Rossor, M., Salloway, S., Stern, Y., Visser, P.J., \& Scheltens, P. (2007). Research criteria for the diagnosis of Alzheimer's disease: Revising the NINCDS-ADRDA criteria. Lancet Neurology, 6, 734-746.

Dux, M.C., Woodard, J.L., Calamari, J.E., Messina, M., Arora, S., Chik, H., \& Pontarelli, N. (2008). The moderating role of negative affect on objective verbal memory performance and subjective memory complaints in healthy older adults. Journal of the International Neuropsychological Society, 14, 327-336.

Ebel, R.L. (1954). Procedures for the analysis of classroom tests. Educational and Psychological Measurement, 14, 352-364.

Feher, E.P., Larrabee, G.J., Sudilovsky, A., \& Crook, T.H., 3rd. (1994). Memory self-report in Alzheimer's disease and in ageassociated memory impairment. Journal of Geriatric Psychiatry \& Neurology, 7, 58-65.

Flicker, C., Ferris, S.H., \& Reisberg, B. (1993). A longitudinal study of cognitive function in elderly persons with subjective memory complaints. Journal of the American Geriatrics Society, 41, 1029-1032.

Folstein, M.F., Folstein, S.E., \& McHugh, P.R. (1975). "Minimental state." A practical method for grading the cognitive state of patients for the clinician. Journal of Psychiatric Research, 12, 189-198.

Franklin, C.L., Repasky, S.A., Thompson, K.E., Shelton, S.A., \& Uddo, M. (2002). Differentiating overreporting and extreme distress: MMPI-2 use with compensation-seeking veterans with PTSD. Journal of Personality Assessment, 79, 274-285.

Franz, C.E., Barker, J.C., Kravitz, R.L., Flores, Y., Krishnan, S., \& Hinton, L. (2007). Nonmedical influences on the use of cholinesterase inhibitors in dementia care. Alzheimer Disease \& Associated Disorders, 21, 241-248.

Gagnon, M., Dartigues, J.F., Mazaux, J.M., Dequae, L., Letenneur, L., Giroire, J.M., \& Barberger-Gateau, P. (1994). Self-reported 
memory complaints and memory performance in elderly French community residents: Results of the PAQUID Research Program. Neuroepidemiology, 13, 145-154.

Galasko, D., Bennett, D., Sano, M., Ernesto, C., Thomas, R., Grundman, M., \& Ferris, S. (1997). An inventory to assess activities of daily living for clinical trials in Alzheimer's disease. The Alzheimer's Disease Cooperative Study. Alzheimer Disease \& Associated Disorders, 11, Suppl 2, S33-S39.

Ganguli, M., Dodge, H.H., Shen, C., \& DeKosky, S.T. (2004a). Mild cognitive impairment, amnestic type: An epidemiologic study. Neurology, 63, 115-121.

Ganguli, M., Gilby, J., Seaberg, E., \& Belle, S. (1995). Depressive symptoms and associated factors in a rural elderly population: The MoVIES Project. American Journal of Geriatric Psychiatry, 3, 144-160.

Ganguli, M., Rodriguez, E., Mulsant, B., Richards, S., Pandav, R., Bilt, J.V., Dodge, H.H., Stoehr, G.P., Saxton, J., Morycz, R.K., Rubin, R.T., Farkas, B., \& DeKosky, S.T. (2004b). Detection and management of cognitive impairment in primary care: The Steel Valley Seniors Survey. Journal of the American Geriatrics Society, 52, 1668-1675.

Geerlings, M.I., Jonker, C., Bouter, L.M., Ader, H.J., \& Schmand, B. (1999). Association between memory complaints and incident Alzheimer's disease in elderly people with normal baseline cognition. American Journal of Psychiatry, 156, 531-537.

Grober, E., Hall, C., Lipton, R.B., \& Teresi, J.A. (2008). Primary care screen for early dementia. Journal of the American Geriatrics Society, 56, 206-213.

Harwood, D.G., Barker, W.W., Ownby, R.L., Mullan, M., \& Duara, R. (2004). No association between subjective memory complaints and apolipoprotein E genotype in cognitively intact elderly. International Journal of Geriatric Psychiatry, 19, 1131-1139.

Jonker, C., Launer, L.J., Hooijer, C., \& Lindeboom, J. (1996). Memory complaints and memory impairment in older individuals. Journal of the American Geriatrics Society, 44, 44-49.

Jorm, A.F., Christensen, H., Korten, A.E., Jacomb, P.A., \& Henderson, A.S. (2001). Memory complaints as a precursor of memory impairment in older people: A longitudinal analysis over 7-8 years. Psychological Medicine, 31, 441-449.

Jungwirth, S., Fischer, P., Weissgram, S., Kirchmeyr, W., Bauer, P., \& Tragl, K.-H. (2004). Subjective memory complaints and objective memory impairment in the Vienna-Transdanube aging community. Journal of the American Geriatrics Society, 52, 263-268.

Kaplan, E., Goodglass, H., \& Weintraub, S. (2001). Boston Naming Test (2nd ed.). Philedelphia: Lippincott Williams \& Wilkins.

Lam, L.C.W., Lui, V.W.C., Tam, C.W.C., \& Chiu, H.F.K. (2005). Subjective memory complaints in Chinese subjects with mild cognitive impairment and early Alzheimer's disease. International Journal of Geriatric Psychiatry, 20, 876-882.

Lavery, L.L., Lu, S.-y., Chang, C.-C.H., Saxton, J., \& Ganguli, M. (2007). Cognitive assessment of older primary care patients with and without memory complaints. Journal of General Internal Medicine, 22, 949-954.

Lopez, O.L., Kuller, L.H., Fitzpatrick, A., Ives, D., Becker, J.T., \& Beauchamp, N. (2003). Evaluation of dementia in the cardiovascular health cognition study. Neuroepidemiology, 22, 1-12.

McDowell, I. \& Newell, C. (1987). Measuring Health: A Guide to Rating Scales and Questionnaires. New York: Oxford University Press.
Mol, M.E.M., van Boxtel, M.P.J., Willems, D., \& Jolles, J. (2006). Do subjective memory complaints predict cognitive dysfunction over time? A six-year follow-up of the Maastricht Aging Study. International Journal of Geriatric Psychiatry, 21, 432-441.

Morris, J.C., Heyman, A., Mohs, R.C., Hughes, J.P., van Belle, G., Fillenbaum, G., Mellits, E.D., \& Clark, C. (1989). The Consortium to Establish a Registry for Alzheimer's Disease (CERAD). Part I. Clinical and neuropsychological assessment of Alzheimer's disease. Neurology, 39, 1159-1165.

Morrow, L., Saxton, J., Snitz, B.E., Zoccolotto, A., \& Eschman, A. (2007). Use of computer-based assessment of mild cognitive impairment in primary care physician offices. Paper presented at the Society for Prevention Research, Washington, DC.

Petersen, R.C., Smith, G.E., Waring, S.C., Ivnik, R.J., Tangalos, E.G., \& Kokmen, E. (1999). Mild cognitive impairment: Clinical characterization and outcome. Archives of Neurology, 56, 303-308.

Reid, L.M. \& Maclullich, A.M.J. (2006). Subjective memory complaints and cognitive impairment in older people. Dementia \& Geriatric Cognitive Disorders, 22, 471-485.

Reitan, R.M. (1958). Validity of the Trail-Making Tests as an indication of organic brain damage. Perceptual and Motor Skills, 8, 271-276.

Saxton, J., Lopez, O.L., Ratcliff, G., Dulberg, C., Fried, L., Carlson, M., Newman, A., \& Kuller, L. (2004). Preclinical Alzheimer's disease: Neuropsychological test performance 1.5 to 8 years prior to onset. Neurology, 63, 2341-2347.

Schmand, B., Jonker, C., Hooijer, C., \& Lindeboom, J. (1996). Subjective memory complaints may announce dementia. Neurology, 46, 121-125.

Small, G.W., Chen, S.T., Komo, S., Ercoli, L., Bookheimer, S., Miller, K., Lavretsky, H., Saxena, S., Kaplan, A., Dorsey, D., Scott, W.K., Saunders, A.M., Haines, J.L., Roses, A.D., \& Pericak-Vance, M.A. (1999). Memory self-appraisal in middleaged and older adults with the apolipoprotein E-4 allele. American Journal of Psychiatry, 156, 1035-1038.

Smith, G.E., Petersen, R.C., Ivnik, R.J., Malec, J.F., \& Tangalos, E.G. (1996). Subjective memory complaints, psychological distress, and longitudinal change in objective memory performance. Psychology \& Aging, 11, 272-279.

Souchay, C. (2007). Metamemory in Alzheimer's disease. Cortex, 43, 987-1003.

Spreen, O. \& Strauss, E. (1998). A Compendium of Neuropsychological Tests. New York: Oxford University Press.

Stewart, R., Russ, C., Richards, M., Brayne, C., Lovestone, S., \& Mann, A. (2001). Depression, APOE genotype and subjective memory impairment: A cross-sectional study in an AfricanCaribbean population. Psychological Medicine, 31, 431-440.

Valcour, V.G., Masaki, K.H., Curb, J.D., \& Blanchette, P.L. (2000). The detection of dementia in the primary care setting. Archives of Internal Medicine, 160, 2964-2968.

van der Flier, W.M., van Buchem, M.A., Weverling-Rijnsburger, A.W.E., Mutsaers, E.R., Bollen, E.L.E.M., Admiraal-Behloul, F., Westendorp, R.G.J., \& Middelkoop, H.A.M. (2004). Memory complaints in patients with normal cognition are associated with smaller hippocampal volumes. Journal of Neurology, 251, 671-675.

Wang, L., van Belle, G., Crane, P.K., Kukull, W.A., Bowen, J.D., McCormick, W.C., \& Larson, E.B. (2004). Subjective memory deterioration and future dementia in people aged 65 and older. Journal of the American Geriatrics Society, 52, 2045-2051. 
Wechsler, D. (1981). Wechsler Adult Intelligence Scale-Revised Manual. New York: The Psychological Corporation.

Wechsler, D. (1987). Wechsler Memory Scale Revised. New York: The Psychological Corporation.

Winblad, B., Palmer, K., Kivipelto, M., Jelic, V., Fratiglioni, L., Wahlund, L.O., Nordberg, A., Backman, L., Albert, M., Almkvist, O., Arai, H., Basun, H., Blennow, K., de Leon, M., DeCarli, C., Erkinjuntti, T., Giacobini, E., Graff, C., Hardy, J., Jack, C., Jorm, A., Ritchie, K., van Duijn, C., Visser, P., \&
Petersen, R.C. (2004). Mild cognitive impairment-beyond controversies, towards a consensus: Report of the International Working Group on Mild Cognitive Impairment. Journal of Internal Medicine, 256, 240-246.

Zandi, T. (2004). Relationship between subjective memory complaints, objective memory performance, and depression among older adults. American Journal of Alzheimer's Disease \& Other Dementias, 19, 353-360.

\section{Appendix 1. Standardized questions assessing change over one year in specific memory-related activities of daily life}

Interviewer: "Now I am going to ask you about some specific activities.

Do you think you are the same, better, or worse than you were a year ago at":

1. Remembering things (events, people, etc.) from a long time ago?

2. Remembering things that happened or were said a few days ago?

3. Remembering appointments, messages, etc.?

4. Remembering names of people you've known for a long time?

5 . Remembering names of people you only met recently?

6. Remembering telephone numbers of people whom you call often?

7. Remembering where you've put things that you use often? (keys, watches, etc.)

8. Remembering how to use familiar appliances, tools, gadgets? (includes car)

9. Learning to use new appliances?

10. Finding the right word to use to describe something you know well? (names of familiar objects etc., not names of people)

11. Remembering what day/date it is?

12. Remembering your way around a familiar neighborhood or street?

13. Remembering a few things you wanted to buy in the store, without writing them down?

14. Remember to do important routine things like turn off the stove or lock the door 